\title{
Description of the training and the associated changes in some biophysical variables of Standardbred racehorses during a racing season
}

\author{
Arno Lindner', Julia Wegener' and Ulrich Hartmann² \\ 1 Arbeitsgruppe Pferd, Jülich, Germany \\ 2 Faculty of Sport Science, University of Leipzig, Germany
}

\begin{abstract}
Summary: The objective of this study was to describe the training and changes in biophysical variables of 2-, 3-, and 4-year-old Standardbred racehorses trained by a successful trainer during a racing season. Methods: The horses were regularly weighed and submitted to standardised exercise tests (SETs) to determine $v_{4}$ (velocity run under defined conditions inducing $4 \mathrm{mmol} / \mathrm{L}$ blood lactate concentration). The training of the horses was protocolled and related to changes in $v_{4}$. The effect of the age of horses on their $v_{4}$ and body weight (BW) was analysed using ANOVA for repeated measures and on training parameters using an univariate ANOVA. The relationship between the changes in $\mathrm{v}_{4}$ and training parameters was examined by means of linear and exponential regressions. Results: The BW of the 3-and 4-year-old horses remained constant during the observation period, whereas it increased for the 2 -year-olds $(P=0.0033)$. Overall, the $v_{4}$ of the 2 -year-olds increased during the racing season $(P=0.043)$, whereas it remained constant for the 3 - and 4 -year-olds. The only differences in the training parameters among the age groups were that the 3 -year-olds were started more frequently than the 2 - and 4 -year-olds $(P=0.037)$, and 2 -year-olds were more often exercised fast than the older horses $(P=0.029)$. The $v_{4}$ changes between consecutive SETs were not attributable to training parameters. The conclusion of this study is that the data collected in a remarkably successful racing stable provides a basis to introduce changes to further optimise the training of Standardbreds.
\end{abstract}

Keywords: exercise, monitoring, lactate, body weight, speed

Citation: Lindner A., Wegener J., Hartmann U. (2019) Description of the training and the associated changes in some biophysical variables of Standardbred racehorses during a racing season. Pferdeheilkunde 35, 498-505; DOI 10.21836/PEM20190602

Correspondence: Dr. Arno Lindner, Arbeitsgruppe Pferd, Heinrich-Röttgen-Str. 20, 52428 Jülich, Deutschland; arnolindner@t-online.de

Received: June 24, 2019

Accepted: August 8, 2019

\section{Introduction}

The objective of training is to enhance the performance of athletes, however, most horses used in sports are trained empirically, including Standardbred racehorses (Lovell 1994, Pringle et al. 1999). The training of Standardbred racehorses has been described in some detail in several studies Unger 1991, Brook 1992, Couroucé 1993, Ponchard 1998, Stahel 2004, Leleu and Haentiens 2010, Fortier et al. 2014), without examining the efficiency of the programmes. Stahel (2004) and Couroucé et al. (2002) only measured the performance parameters $v_{4}$ (velocity run under defined conditions inducing a blood lactate concentration of $4 \mathrm{mmol} / \mathrm{L}$ lactate) and $\mathrm{v}_{200}$ (velocity run under defined conditions inducing a heart rate of 200 beats $/ \mathrm{min}$ ) during a racing season but did not relate training parameters to the changes in the values.

Before changes are introduced in a successful training system evolved over time, an evaluation of the efficiency of the training should be performed. Therefore, in this study, 2-, 3- and 4 -year-old Standardbred racehorses of a very successful trainer (Wegener 2000, Wegener et al. 2012) were monitored during a racing season. It was hypothesised that: 1) the body weight and $v_{4}$ of horses would change over time; 2) training differs among 2-, 3-and 4-year-olds; and 3) training parameters are related to changes in $v_{4}$.

\section{Material and Methods}

Data for this study was collected during routine commercial exercise testing to monitor the fitness of horses. The horse owner consented to all procedures.

Trainer

The trainer was one of the most successful in Germany in the decade 1990 to 2000. He allowed a full insight into his training. Several of his horses won the German Derby and competed at the highest international levels. From 1997 to 2000 , between $25 \%$ and $30 \%$ of his starters won the race in which they were started (Hauptverband für Traber-Zucht 1997-2000). The data of this study was obtained in the year 1999 (Wegener 2000). 


\section{Horses}

The health and performance of the horses was monitored continuously by veterinary surgeons. The monitoring involved weighing the horses every second week and determining as regularly as possible their $\mathrm{v}_{4}$ (velocity run under defined conditions inducing $4 \mathrm{mmol} / \mathrm{L}$ blood lactate concentration [LA]). The aim was to test each horse in intervals of about 2 months.

The number of horses used to test the different hypotheses of this study varied. To evaluate changes in body weight (BW), horses were weighed every 2 weeks between mid-January and the end of July. There were available the data for six 2-year olds, 12 3-year-olds and eight 4-year-olds for this evaluation.

The change in $v_{4}$ during the observation period was examined testing four 2-year-olds, five 3-year-olds, and four 4 -year-olds every 2 months. Other five 2 -year-old horses had been tested twice the year before the study and were tested two more times as 3-year-olds to describe the development of their $v_{4}$ between 2 seasons.

The training was protocolled for three 2-year-olds, three 3-year-olds, and two 4-year-olds. The effect of training parameters on $v_{4}$ changes was investigated using these horses only.

Training

From 10th May until 30th September, the duration of the daily exercise for three 2-year-old, three 3-year-old, and two 4 -year-old horses was measured by an observer with a stopwatch and the distance covered recorded (Wegener et al. 2012). The horses were exercised fast on an $800 \mathrm{~m}$ sandy track. Slow work was done on an 1,800 m sandy track. The $v_{4}$ of these horses was determined three times at intervals of 2 months during the observation period and changes in the values related to the following training parameters between consecutive SETs: the number of days with fast work, the number of days with slow work, the number of days with a start, the number of days without training (horse was not exercised on either track), the $\%$ of days with fast work, the $\%$ of days with slow work, the $\%$ of days with a start, and the $\%$ of days without training, as well as the total duration of fast work, the total duration of sprinting during fast work, and the total duration of slow work.

\section{Standardised exercise test}

The standardised exercise test (SET) prescription differed between the 2-year-olds and the older horses (Table 1), but for five 2 -year-old horses that were tested 2 more times when they were 3-year-old with the SET prescription for the 2-year-olds to be able to compare their results.

All horses were tested in intervals of about 2 months. During the SET, the drivers constantly used a stop-watch to set the prescribed pace. Before each SET, the track was groomed to ensure regular lane conditions. The horses were warmed up for between 10 and 15 min at a walk and slow trot before starting the SET. The increase in speed from interval to interval was such that a continuous increase in the blood [LA] from the concentration before exercise but after warm-up to $\geq 4 \mathrm{mmol} / \mathrm{L}$ was obtained in no less than four intervals of approximately 5 min each (Table 1). This was done to obtain at least four valves to describe the blood lactate-running speed relationship (BLRS) and to run the horses as slow as possible to obtain the $4 \mathrm{mmol} / \mathrm{L}$ of blood [LA]. The SET was discontinued when the blood [LA] of the horses was at or above $4 \mathrm{mmol} / \mathrm{L}$ (determined on site using Accusport, Boehringer Mannheim, Mannheim, Germany). The horses always started and finished an interval at the same place. This place was near to the entrance of the $800 \mathrm{~m}$ track, so that the horses could be taken out of the track within seconds of finishing an interval and blood samples could be taken generally within $20 \mathrm{~s}$ after an interval. This was done to ensure that other horses exercising on the track would not be disturbed. The intervals were separated by a period of $3 \mathrm{~min}$. This was sufficient time to walk the horses back to the track to start the next interval. An independent observer with a stop-watch accurate to $0.1 \mathrm{~s}$ timed every lap of each interval. With the measured blood [LA] and running speed for each interval of the SET, $v_{4}$ was calculated from the BLRS relationship by an exponential regression analysis (Galloux 1991). The mean heart rate (HR) during each interval of a SET was plotted linearly against the speed of each interval, and $v_{200}$ was calculated from this relationship (Table 1).

Lactate

Blood ( $5 \mathrm{~mL}$ ) was sampled by venipuncture from a jugular vein after warm-up and before commencing the SET, and as soon as possible after each interval of SET, normally within 20 s, into Na-heparinised evacuated tubes (Becton Dickinson, Heidelberg, Germany) for the determination of blood $[\mathrm{LA}]$. The blood [LA] was measured on site with an Accusport. The coefficient of variance between measurements was below $5 \%$.

\section{Physical variables}

The horses wore a commercial heart rate (HR) monitor attached to the thorax during SET (Polar Sport Tester, Kempele,

Table 1 Standardised exercise test prescribed for 2-year-old and older Standardbred racehorses. The sand-track was $800 \mathrm{~m}$ long | Standardisierte Belastungstests für 2-Jährige und ältere Trabrennpferde. Die Länge der Sandbahn betrug $800 \mathrm{~m}$

\begin{tabular}{c|cc|cc}
\hline Interval & \multicolumn{2}{|c|}{ 2-year-olds } & \multicolumn{2}{c}{$>$ 2-year-olds } \\
\hline & Distance $(\mathrm{m})$ & $\mathrm{v}(\mathrm{m} / \mathrm{s})$ & Distance $(\mathrm{m})$ & $\mathrm{v}(\mathrm{m} / \mathrm{s})$ \\
\hline 1. & 2,400 & 6.00 & 2,400 & 6.67 \\
\hline 2. & 2,400 & 6.67 & 2,400 & 7.50 \\
\hline 3. & 2,400 & 7.33 & 2,400 & 8.33 \\
4. & 2,400 & 8.00 & 3,200 & 9.17 \\
5. & 2,400 & 8.67 & 3,200 & 10.00 \\
\hline 6. & 3,200 & 9.33 & 3,200 & 10.83 \\
\hline
\end{tabular}

$v=$ velocity 
Finland). The monitor recorded the HR every $5 \mathrm{~s}$. The mean HR (HRmean) of each interval of the SET was calculated. The body weight (BW) was obtained by weighing the horses on a scale (Horse Weight, Wales, UK) every second week. The accuracy of the scale was $\pm 100 \mathrm{~g}$.

\section{Data Analysis}

The normality of the data was confirmed using the Kolmogorov-Smirnov test. Data are presented as mean \pm SD. The changes over time in $v_{4}$ and BW were analysed using a twoway ANOVA for repeated measures and the difference in age categories on training parameters were analysed using a univariate ANOVA. Fisher's exact test was applied when significant effects were detected. The relationship between the difference in $v_{4}$ values between SETs and the training, as well as between the $v_{4}$ and $v_{200}$ of the horses, was examined by means of linear and exponential regressions. The significance level was set at $P<0.05$.

\section{Results}

The BW of the 3- and 4-year-old horses remained constant during the observation period $(P>0.05$; Fig. 1), whereas it increased for the 2 -year-olds $(P=0.0033)$. The increase between weighing dates was significant between day 115 and all weighing days after day 150 and following (all $P<0.001$ ). The BW of the 2-year-old horses was lower than of the 4-yearold horses during the observation period $(P=0.039)$, however, there was no significant difference between the 2- and 3 -year-old or the 3 - and 4 -year-old horses $(P>0.05)$.

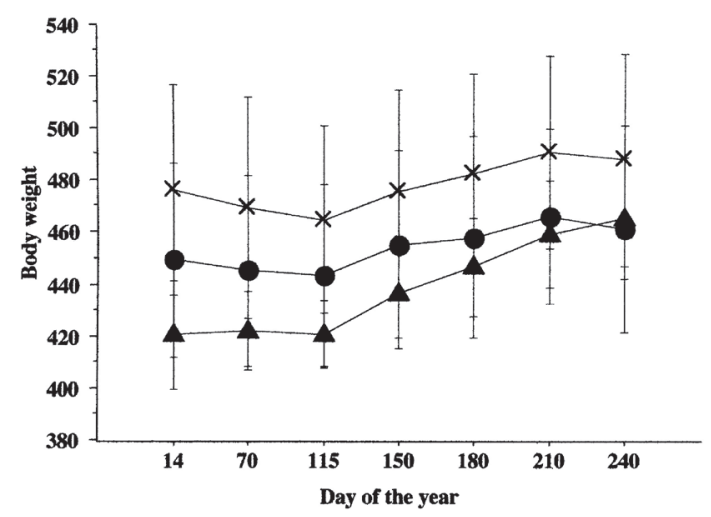

Fig. 1 Changes in body weight ( $\mathrm{kg}$; BW) of Standardbred horses of different ages during a racing season (mean $\pm \mathrm{SD} ; \boldsymbol{\Lambda}=$ six 2 -yearolds; $=$ twelve 3 -year-olds; $X=$ eight 4 -year-old; $P=0.039$ comparing the BW of 2-year-olds to that of 4 -year-olds; $P>0.05 \mathrm{com}$ paring the BW of 2-and 3-year-old and 3-and 4-year-old horses. The BW of 3- and 4-year-old horses remained constant during the observation period $(P>0.05)$, whereas it increased for the 2-yearolds $(P=0.0033)) \quad$ Entwicklung des Körpergewichts (KGW) von Trabrennpferden unterschiedlichen Alters während einer Rennsaison ( $\mathrm{kg}$; Mittelwert \pm Standardabweichung; $\boldsymbol{\Delta}=$ sechs 2-Jährige; $\mathbf{O}=12$ 3-Jährige; $x=$ acht 4-Jährige; $P=0,039$ zwischen dem KGW von 2- und 4-Jährigen; $P>0,05$ zwischen dem KGW von 2- und 3-Jährigen sowie dem KGW der 3- und 4-Jährigen; Das KGW der 3- und 4-Jährigen blieb konstant $(P>0,05)$ während das der 2-Jährigen im Verlauf des Beobachtungszeitraums stieg $(P=0,0033))$
The $v_{4}$ of the 2 -year-olds increased during the racing season (Fig. 2; $P=0.043$ between April and August, $P>0.05$ between April and June as well as between June and August) but remained constant for the 3 - and 4-year-olds $(P=0.93$ and $P=0.27$, respectively). The $v_{4}$ of 3 - and 4 -year-olds did not differ $(P>0.05)$. The $v_{4}$ of the 2 -year-old horses was lower than that of the older horses but values cannot be compared statistically because the SET prescriptions were different.

The mean $v_{4}$ of the five horses that were tested with the SET prescribed for 2-year-olds in their 2-and 3-year-old racing season increased significantly $(P<0.001)$. The $v_{4}$ values were higher in both testing dates for the 3-year-olds than for the 2 -year-olds $(P<0.01$ to 0.001$)$. There were no differences between the mean $v_{4}$ values determined when the horses were 2 -year-old or when 3-year-old $(P>0.05$ for the 2 -year-olds between May and September and $P=0.07$ for the 3-yearolds between March and May) (Fig. 3).

There were few differences in the training parameters of the Standardbreds of different ages (Table 2). Horses that were 3 years old started more frequently than 2 - and 4 -year-olds $(P=0.037$; the latter holds true for the 4-year-olds only for the $\%$ of starting days between consecutive SETs: $P=0.0026)$. In addition, 2-year-olds were more often exercised fast than the older horses $(P=0.029)$.

The $v_{4}$ changes between consecutive SETs could not be attributed to any of the training parameters examined $(P>0.05$ for all).

The development of $v_{200}$ during the racing season could not be examined because too often the HR monitors failed to record the HR during the SETs.

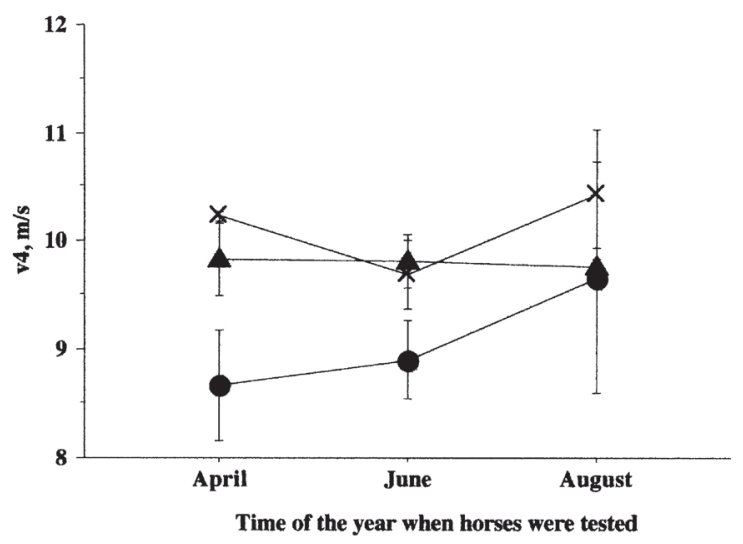

Fig. 2 Changes in $v_{4}(\mathrm{~m} / \mathrm{s}$; velocity run under defined conditions inducing $4 \mathrm{mmol} / \mathrm{L}$ blood lactate concentration) of Standardbred racehorses of differing ages during a racing season (mean \pm SD; $\boldsymbol{\Delta}=$ four 2 -year-olds; $\mathbf{O}=$ five 3 -year-olds; $x=$ four 4 -year-olds; the $v_{4}$ of 2 -year-olds during the racing season increased $(P=0.043)$, whereas the $v_{4}$ of 3 - and 4 -year-olds remained constant $\left.(P>0.05)\right)$ Entwicklung der $v_{4}$ von Trabrennpferden unterschiedlichen Alters während einer Rennsaison $\left(v_{4}=\right.$ Geschwindigkeit bei der unter den gegebenen Bedingungen die Laktatkonzentration im Blut $4 \mathrm{mmol} / \mathrm{l}$ beträgt; Mittelwert \pm Standardabweichung; $\boldsymbol{\Delta}=$ vier 2-Jährige; $\mathbf{O}=$ fünf 3-Jährige; $x=$ vier 4-Jährige; Zunahme der $v_{4}$ von 2-Jährigen während der Rennsaison $(P=0,043)$ während es bei den 3- und 4-Jährigen keine Änderung gab $(P>0,05))$ 
There was no relationship between the $v_{4}$ and $v_{200}$ of 2 -yearolds or of older horses ( $P>0.05$ for both; 72 -year-olds and 15 older horses with a total of 10 and 20 SETs used to calculate the relationship, respectively). The relationship between $v_{4}$ and $v_{200}$ approached significance when the data were pooled $\left(r^{2}=0.12, P=0.06\right)$.

\section{Discussion}

The $v_{4}$ of the horses was regularly determined in this very successful racing yard to monitor their response to the training and to diagnose their likelihood of racing success (Wegener 2000, Wegener et al. 2012). Many authors have shown a strong relationship between $\mathrm{v}_{4}$ and the racing performance of Standardbred racehorses (Casini and Greppi 1996, Couroucé 1997, Couroucé et al. 1997, Ponchard 1998, Leleu et al. 2004, 2005, Lindner 2010) and therefore, the aim of training Standardbreds could be to increase their $v_{4}$. There was observed a significant increase of the $v_{4}$ of the 2 -yearolds during the racing season and between May of their year as 2-year-olds and May of their year as 3-year-olds, whereas the $v_{4}$ of the 3 - and 4-year-olds remained constant from the beginning of April to the end of August.

The $v_{4}$ of the 2 -year-old Standardbreds was lower than the $v_{4}$ of the 3-and 4-year-olds due to their lower endurance and not due to the different SET prescriptions for 2-year-olds and older horses. If the SET prescription for the 2-year-olds had been applied to the older horses, they would have reacted to the lower speeds in the intervals with lower blood [LA], and this would have made it necessary to have them run additional intervals at higher speed to raise their blood lactate concentration above $4 \mathrm{mmol} / \mathrm{L}$, without obtaining more information on their endurance. This has been described before using different SET prescriptions to test Standardbred horses of different ages (Couroucé 1997, Couroucé et al. 1997) or the same SET prescription for all ages (Lindner 2010).
The changes in $v_{4}$ of the 2 -year-olds could be due the training. However, the assumption remains speculative since several other factors besides the training program could have had an influence. Changes in muscle enzyme activities and muscle fibre morphology due to aging might have contributed to the $\mathrm{v}_{4}$ increase in the younger horses (Essen-Gustavsson et al. 1983, Henckel 1983, Roneus et al. 1987, Eto et al. 2003). In addition, the growth reflected in the increase in the BW of the 2-year-olds might have had an influence. Only one study was found in the literature that described the changes in BW of 2-year-old Standardbreds in France during an observation

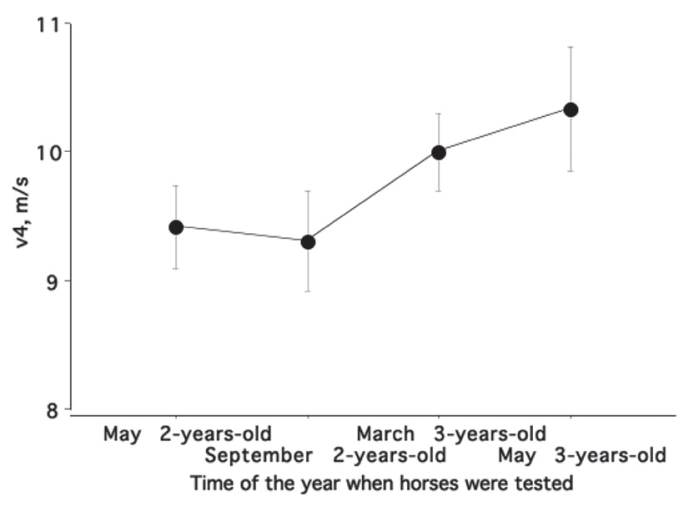

Fig. 3 Changes in $v_{4}(\mathrm{~m} / \mathrm{s})$ of five Standardbred racehorses from the year when they were 2 years old to the year when they were 3 years old $\left(v_{4}=\right.$ velocity run under defined conditions inducing $4 \mathrm{mmol} / \mathrm{L}$ blood lactate concentration; mean $\pm \mathrm{SD} ; P<0.001$ between values when 2 -year-old compared to values when 3 -year-old, but $P>0.05$ between values when 2 -year-old or when 3-year-old) Entwicklung der $v_{4}(\mathrm{~m} / \mathrm{s})$ von fünf Trabrennpferden, die zu Beginn der Beobachtung 2-jährig und zum Ende 3-jährig waren $\left(v_{4}=\right.$ Geschwindigkeit bei der unter den gegebenen Bedingungen die Laktatkonzentration im Blut $4 \mathrm{mmol} / \mathrm{l}$ beträgt; Mittelwert \pm Standardabweichung; Zunahme der $v_{4}$ zwischen den Terminen als 2-Jährige und 3-Jährige Pferde $(P<0,001)$ aber keine Unterschiede zwischen den Werten 2-jährig oder 3-jährig $(P>0,05)$

Table 2 Training of Standardbred racehorses during the racing season between consecutive standardized exercise tests (three 2-year-olds, three 3-year-olds, and two 4-year-olds; mean \pm SD; s = seconds). | Training von Trabrennpferden während der Rennsaison zwischen aufeinanderfolgenden Belastungstests (drei 2-Jährige, drei 3-Jährige und zwei 4-Jährige; Mittelwert \pm Standardabweichung; s = Sekunden)

\begin{tabular}{lccc}
\hline Training parameter & 2-year-olds & 3-year-olds & 4 -year-olds \\
\hline Days between SET & $52.5 \pm 17.5$ & $47.0 \pm 25.5$ & $63.5 \pm 20.5$ \\
\hline Days with fast work & $12.5 \pm 5.00$ & $8.33 \pm 4.04$ & $9.00 \pm 2.83$ \\
\hline Days with slow work & $15.8 \pm 6.34$ & $15.0 \pm 10.8$ & $22.5 \pm 10.6$ \\
\hline Days with a start & $0.50 \pm 0.58 a$ & $3.67 \pm 1.53 a$ & $3.00 \pm 2.83$ \\
\hline Days without training & $21.0 \pm 7.39$ & $16.7 \pm 7.10$ & $18.5 \pm 3.54$ \\
\hline of days with fast work & $23.3 \pm 2.35 a, b$ & $18.2 \pm 1.30 a$ & $14.2 \pm 0.13 b$ \\
\hline of days with slow work & $30.0 \pm 4.69$ & $30.4 \pm 6.44$ & $34.5 \pm 5.55$ \\
\hline of days with a start & $0.77 \pm 0.89 a, b$ & $8.27 \pm 1.29 a, c$ & $4.23 \pm 3.09 b, c$ \\
\hline of days without training & $40.0 \pm 4.71$ & $37.4 \pm 5.46$ & $29.8 \pm 4.05$ \\
\hline Total duration of fast work, s & $24,350 \pm 9,740$ & $16,083 \pm 7,800$ & $17,163 \pm 5,394$ \\
\hline Total duration of sprinting during fast work, s & $4,938 \pm 1,975$ & $3,333 \pm 1,617$ & $3,582 \pm 1,126$ \\
\hline Total duration of slow work, s & $41,816 \pm 16,563$ & $50,295 \pm 36,268$ & $75,600 \pm 35,638$ \\
\hline
\end{tabular}

Same letters among age groups denote $P<0.05$ 
period of three months until mid-April (Leleu and Haentjens 2010). The BW of most of their horses increased, however, a few lost BW. Leleu and Haentiens (2010) attributed the BW loss of their horses to an energy imbalance due to excess energy expenditure during exercise, rather than an insufficient energy supply. The practical value of their results is unknown since the data on the fitness parameters of the horses were not published.

Concerning the possible effect of training, the higher number of days with fast work for the 2-year-olds appeared to have had a positive effect on the $v_{4}$. However, the general training alone might have produced the effect, despite the significant finding for singular training parameters. The level of $v_{4}$ needs to be considered too, since it is easier to increase a low $v_{4}$ than a high $v_{4}$, regardless of the type of exercise used. Finally, the racing season has periods with an accumulation of important races for horses of certain age groups. The 4-yearolds can start during most of the year. In contrast, 3-year-olds will receive more attention in training to get them race fit during June to early September of a year in Germany, and 2-year-olds will start to race more frequently only in August. Thus, the racing system dictates a periodisation of the training for horses of different ages, although this was not very evident in this study, except for the number of races and days with fast work. It is possible that the trainer might have aimed to keep his 3- and 4-year-old horses sound during their main racing season and, thus, the training was kept at a constant level that did not increase $v_{4}$ to higher levels than those measured at the beginning of the study. Similar results have been described by Couroucé (1993). Stahel (2004) also observed that the $v_{4}$ and $v_{200}$ of Standardbreds older than 2 years of age trained by an amateur trainer did not change much during a racing season.

In general, the training followed was quite similar for the horses in all age groups. The main difference was found for the number and percentage of days with a start between two consecutive SET. Not surprisingly, it was lowest for the 2-yearolds and highest for the 3-year-olds. The German Derby is always at the beginning of August and, therefore, the trainer favoured racing his 3-year-olds during the period in which the training was documented in detail. The other significant difference among the age groups was that the 2-year-olds were more often worked fast than the older horses.

The training parameters examined in this study had no significant effect on the $v_{4}$ values of horses between consecutive SETs. This finding is likely to be due to the limited number of horses evaluated and the moderate changes in $v_{4}$. The number of studies on the relationship between training in practice and parameters of fitness such as $v_{4}, v_{200}$ or peak oxygen uptake is very limited. Couroucé et al. (2002) only showed that $v_{4}$ and $v_{200}$ were related to the training state of Standardbred racehorses over 2 years of age when horses were already competing, and not when they were still being prepared for competition.

A few authors have demonstrated that $v_{200}$ also has some value in estimating the performance of Standardbreds (Leleu et al. 2005), however, most were unable to show this (Couroucé 1997, Ponchard 1998, Leleu et al. 2004, Lindner 2010). The trainer involved in this study was not very fond of using heart rate monitors on his horses due to the time required to set them up, the number of occasions when the data could not be recorded, and the reduced practical value of the information. Ponchard (1998) encountered the same situation with the trainers involved in his study. Thus, it was not possible to collect data of sufficient horses with consecutive recordings of their $v_{200}$ to describe the development during the racing season and study the effects of the training parameters.

In this study, no relationship was found between the $v_{4}$ and $v_{200}$ of 2-year-olds and of older horses. By pooling the data, a trend for these parameters to be positively related was shown. Ponchard (1998) observed the same, whereas Persson (1983) and Couroucé (1997) described a good relationship between the $v_{4}$ and $v_{200}$ of trotters. Couroucé (1997) determined the relationship between the $v_{4}$ and $v_{200}$ values with 290 SETs of 211 trotters of all ages using different SET prescriptions for horses of different ages. The different SET prescriptions among age groups produced a wider spread of $v_{4}$ and $v_{200}$ values than in this study and the study by Ponchard (1998). This, combined with the large number of comparisons, increases the likelihood of determining a significant relationship. It is also possible that the different SET prescriptions contribute to the divergence of results among studies. The speed and duration of exercise affect the blood [LA], whereas heart rate is influenced by speed only and not by duration, at least within the range of time that is normally used to run SETs. In addition, the blood [LA] is exponentially related to the speed of exercise, whereas heart rate is related linearly to it (Persson 1983). Therefore, it seems plausible that there is no relationship between these two parameters.

In conclusion, despite of the low number of horses involved in the study, the data collected in a remarkably successful racing stable (Wegener 2000, Wegener et al. 2012) provides a basis to optimise the training of Standardbreds by examining the effect of diverse exercises, for example of blood lactate-guided exercises (Werkmann et al. 1996, Gansen et al. 1999, Trilk et al. 2002, Rivero et al. 2006, 2007, Lindner et al. 2009a, $2009 b, 2010,2013)$, and frequencies on their $v_{4}$, the parameter most often shown to be related with racing performance of Standardbred racehorses (Casini and Greppi 1996, Couroucé 1997, Couroucé et al. 1997, Ponchard 1998, Leleu et al. 2004, 2005, Lindner 2010).

\section{Conflict of interests}

None

\section{References}

Brock A. (1992) Veränderungen der Laktat-, Glucose- und Biopterinspiegel im jugularvenösen Blut von Trabrennpferden bei unterschiedlichen Belastungen. Doctoral thesis, Veterinary Medicine, University of München, Germany

Casini L., Greppi G. F. (1996) Correlation of racing performance with fitness parameters after exercise tests on treadmill and on track in Standardbred racehorses. Pferdeheilkunde 12, 466-469

Couroucé A. (1993) Contribution a l'evaluation de la charge de travail du cheval trotteur a l'entreinament et en course. Diploma thesis, Veterinary Medicine, University of Nantes, France 
Couroucé A. (1997) Epreuve d'effort standardise de terrain apliquee au cheval trotteur. PhD thesis, University of Saint Etienne, France

Couroucé A., Chatard J. C., Auvinet B. (1997) Estimation of performance potential of Standardbred trotters from blood lactate concentrations measured in field conditions. Equine Vet. J. 29, 365-369

Couroucé A., Chrétien M., Valette J. P. (2002) Physiological variables measured under field conditions according to age and state of training in French trotters. Equine Vet. J. 34, 91-97

Essen-Gustavsson B., Lindholm A., Persson S. G. B., Thornton J. (1983) Skeletal muscle characteristics of young Standardbreds in relation to growth and early training. In Equine Exercise Physiology 1. (eds.) D. H. Snow, S. G. B. Persson, R. J. Rose. Granta Editions, Cambridge, UK. pp 200-210

Eto D., Yamano S., Kasashima Y., Sugiura T., Nasu T., Tokuriki M., Miyata H. (2003) Effect of controlled exercise on middle gluteal muscle fibre composition in Thoroughbred foals. Equine Vet. J. $35,676-680$

Fortier J., Julliand V., Harris P., Goachet A. G. (2014) Training management of Standardbred trotters: a field survey in France. Comp. Exercise Physiol. 10, 63-71

Galloux P. (1991) Contribution à l'élaboration d'une planification de la préparation énergétique du cheval de concours complet suivi de l'entraînement par la mesure de la fréquence cardiaque et le dosage de la lactatémie. PhD thesis, University of Poitiers, France

Gansen S., Lindner A., Marx S., Mosen H., Sallmann H. P. (1999) Effects of conditioning horses with lactate-guided exercise on muscle glycogen content. Equine Vet. J. Suppl. 30, 329-331

Hauptverband für Traber-Zucht. 1997-2000. Trainerstatistik. www.hvt.de

Henckel P. (1983) Training and growth induced changes in the middle gluteal muscle of young statdardbred trotters. Equine Vet. J. $15,134-140$

Leleu C., Cotrel C., Barrey E. (2004) Predictive interest of physiological and gait variables in French trotters. In The Elite Race and Endurance Horse - CESMAS. (ed.) A. Lindner. Arbeitsgrupppe Pferd, Jülich, Germany. pp 189-193

Leleu C., Cotrel C., Courouce-Malblanc A. (2005) Relationships between physiological variables and race performance in French standardbred trotters. Vet. Rec. 156, 339-342

Leleu C., Haentiens F. (2010) Morphological, haemato-biochemical and endocrine changes in young Standardbreds with 'maladaptation' to early training. Equine Vet. J. 42, 171-178

Lindner A. (2000) Use of blood biochemistry for positive performance diagnosis of sport horses in practice. Revue Médécine Vétérinarie $151,611-618$

Lindner A. (2010) Relationships between racing times of Standardbreds and $v_{4}$ and $v_{200}$. J. Anim. Sci. 88, 950-954

Lindner A., Mosen H., Kissenbeck S., Fuhrmann H., Sallmann H. P. (2009a) Effect of blood lactate-guided conditioning of horses with exercises of differing duration and intensities on heart rate and biochemical blood variables. J. Anim. Sci. 87, 3211-3217

Lindner A., López R. A., Durante E., Ferreira V., Boffi F. M. (2009b) Conditioning horses at v10 3 times per week does not enhance $v_{4}$. J. Equine Vet. Sci. 29, 828-832
Lindner A., López R. A., Durante E., Hernandez H., Botta V., Sadaba S., Boffi F. M. (2011) Effect of conditioning horses every third day at $\mathrm{v}_{10}$ on measures of fitness. J. Anim. Nutrition Anim. Physiol. 95, 286-293

Lindner A., Dag Erginsoy S., Kissenbeck S., Mosen H., Hetzel U., Drommer W., Chamizo V. E., Rivero J. L. L. (2013) Effect of different blood-guided conditioning programmes on skeletal muscle ultrastructure and histochemistry of sport horses. J. Anim. Physiol. Anim. Nutrition 97, 374-386

Lovell D. (1994) Training Standardbred Trotters and Pacers. In:The athletic horse: principles and practice of equine sports medicine. (eds.) D. R. Hodgson \& R. J. Rose. Saunders, Philadelphia, USA. pp 399-408

Persson S. G. B. (1983) Evaluation of exercise tolerance and fitness in the performance horse. In: Equine Exercise Physiology 1. (eds.) D. H. Snow, S. G. B. Persson \& R. J. Rose. Granta Editions, Cambridge, UK. pp 441-457

Ponchard M. T. (1998) Equine Exercise prescription and talent identification based on plasma lactate kinetics. PhD thesis, University of Western Australia, Perth, Australia

Pringle J., MacMillan K., Briand H., Staempfli H. (1999) Comparison of exercise variables measured during intensity of simulated training to variables at maximal effort in Standardbreds. Equine Vet. J. Suppl. 30, 166-169

Rivero J. L. L., Ruz A., Marti-Korff S., Lindner A. (2006) Contribution of exercise intensity and duration to training-linked myosin transitions in Thoroughbreds. Equine Vet. J. Suppl. 36, 311-315

Rivero J. L. L., Ruz A., Marti-Korff S., Estepa J. C., Aguilera-Tejero E., Werkmann J., Sobotta M., Lindner A. (2007) Effects of intensity and duration of exercise on muscular responses to training of Thoroughbred racehorses. J. Appl. Physiol. 102, 1871-1882

Ronéus M., Essén-Gustavsson B., Lindholm A., Persson S. G. B. (1987) A field study of circulatory response and muscle characteristics in young Thoroughbreds. In: Equine Exercise Physiology 2. (eds.) J. R. Gillespie, N. E. Robinson. ICEEP Publications, Davis, CA, USA. pp 376-383

Stahel S. (2004) Erhebung von Trainingsintensitäten und -umfang bei Trabrennpferden in der Schweiz. Doctoral thesis, Veterinary Medicine, University of Zürich, Switzerland

Trilk J. L., Lindner A., Greene H. M., Alberghina D., Wickler S. J. (2002) A lactate-guided conditioning program to improve endurance performance. Equine Vet. J. Suppl. 34, 122-125

Unger G. A. (1991) Leistungsphysiologische Untersuchungen bei Trabern. Doctoral thesis Veterinary Medicine, University of München, Germany

Wegener J. (2000) Dokumentation und exemplarische Darstellung des Trainings von Trabrennpferden. Diplomarbeit, Sporthochschule Köln

Wegener J., Lindner A., Hartmann U. (2012) Survey on the training of Standardbred racehorses by a successful trainer. Pferdeheilkunde 28, 268-280

Werkmann J., Lindner A., Sasse H. H. L. (1996) Conditioning effects in horses of exercise of 5, 15 or 25 minutes' duration at two blood lactate concentrations. Pferdeheilkunde 12,474-479 